Research Article

\title{
Demucilaging Freshly Stored Seeds of Cocoa (Theobroma cacao L.) Improves Seedling Emergence and Growth
}

\author{
Michael O. Adu, ${ }^{1}$ Thomas Cobbinah, ${ }^{1}$ Paul A. Asare, ${ }^{1}$ \\ David O. Yawson, ${ }^{2}$ and Kingsley J. Taah ${ }^{1}$ \\ ${ }^{1}$ Department of Crop Science, School of Agriculture, College of Agriculture and Natural Sciences, University of Cape Coast, \\ Cape Coast, Ghana \\ ${ }^{2}$ Department of Soil Science, School of Agriculture, College of Agriculture and Natural Sciences, University of Cape Coast, \\ Cape Coast, Ghana
}

Correspondence should be addressed to Michael O. Adu; michael.adu@ucc.edu.gh

Received 25 November 2016; Accepted 26 December 2016; Published 22 January 2017

Academic Editor: Curtis C. Daehler

Copyright (C) 2017 Michael O. Adu et al. This is an open access article distributed under the Creative Commons Attribution License, which permits unrestricted use, distribution, and reproduction in any medium, provided the original work is properly cited.

\begin{abstract}
Fresh seeds of cocoa (Theobroma cacao L.) are covered by a large amount of mucilage, which plays important ecological roles. However, for stored seeds, mucilage can adversely affect germination. This study investigated the effect of mucilage removal (demucilaging) and seed storage of freshly extracted cocoa seeds on seedling emergence and growth. The study showed that demucilaging cocoa seeds confers several advantages over mucilage intact seeds provided the seeds have been stored for at least three days before sowing. Demucilaging increased germination rate $\left(\mathrm{T}_{50}\right)$ and percentage germination and presence of mucilage increased days to seedling emergence and cessation of germination when seeds were stored for over two days. For up to 21 days of seed storage, there was generally no difference in many traits for demucilaged seeds. Demucilaged seeds had $80-100 \%$ germination after 21 days of storage, and rate of germination increased with increasing duration of seed storage. Intact mucilage seeds maintained $80-100 \%$ germination for only 2 days after seed extraction and rate of germination decreased with increasing seed storage duration. We conclude that (i) if seeds are sown on the day of extraction demucilaging before sowing would be superfluous and (ii) demucilaging and storage can provide advantages to smallholder farmers when environmental or socioeconomic conditions preclude immediate sowing.
\end{abstract}

\section{Introduction}

Cocoa (Theobroma cacao L.) is a major plantation crop in Ghana, contributing considerably to the Government's revenue and gross domestic product (GDP). Cocoa generates about $\$ 2$ billion foreign exchange annually and employs and provides livelihoods for about 800,000 families located in the seven cocoa regions in Ghana (http://www.snv.org/ project/cocoa-eco-project-accessed: 30/09/2016). Approximately $90 \%$ of total cocoa production in Ghana is undertaken by smallholder farmers with an average farm size of 5 acres ([1]; http://www.snv.org/project/cocoa-eco-project accessed: 30/09/2016). Although the Ghana Cocoa Board
(COCOBOD) distributes improved cocoa seedlings freely to farmers, many farmers, particularly those in remote areas, still produce their own seedlings or sow directly from their own seed stock. This practice is due to gaps in the cocoa seedling distribution programme (as revealed by informal interactions with farmers) such as substantial seasonal and yearly fluctuations and occasional inadequacy of seedlings for all registered farmers. Further, farmers in remote areas have constraints to accessing seedlings as farmers in all the cocoa producing areas in Ghana depend on only 26 seed gardens (cocoa stations), operated by COCOBOD, for the supply of planting materials [2]. Consequently, pods of improved genetic materials are normally transported over 
long distances to farmers' fields. In addition to the bulkiness of the pods, lengthy storage durations during transportation have been a limitation [2].

For most smallholder cocoa farmers in Ghana, pods are stored for some time before sowing but the seeds can lose viability and vigour under a long period of handling or storage [2]. Furthermore, cocoa seeds are recalcitrant, implying that they are short-lived, and unable to survive desiccation when extracted from the pods [3]. Additionally, postharvest handling techniques could lead to intragenotypic variation in growth rate in seedlings raised from the same pod. This may lead to the production of nonuniform seedlings, a situation that may be avoided if germination could be synchronised [4]. Postharvest seed handling is therefore critical for seed viability and fortunately it is the most controllable among the factors affecting germination and development of cocoa seedlings [4].

Establishment of cocoa plants is determined by mechanisms that ensure germination and seedling development [5]. A wide range of genotypic and environmental factors, including varietal effects, pod and bean characteristics, storage, and seed treatment, influence germination and subsequent seedling emergence of cocoa [4]. When extracted fresh, cocoa seeds are glued together on the placenta by the sticky mucilage on the seed coat and this mucilage is said to play a crucial role in germination. The presence of mucilage on the seed coat protects the plant against drought stress during germination and early seedling growth [6]. Seed mucilage functions in uptake of water to increase and stabilize water potential surrounding the seed, thereby facilitating efficient germination and seedling establishment, especially in arid conditions [7]. However, informal interactions with famers revealed that, for stored cocoa seeds, presence of mucilage adversely affects germination. Hence, smallholder farmers either remove the seed mucilage before sowing or discard seeds meant for sowing after three days of storage. The objective of this work was to evaluate the effect of storage and mucilage on seed germination, seedling growth, and seedling root system architecture (RSA) of cocoa in the nursery under replete water supply conditions.

\section{Materials and Methods}

2.1. Genetic Material. The genetic material used for this study was the hybrid clone PA 07. This is a Parinari clone characterised by rapid growth, early maturity, high yield, and drought tolerance [8]. Its local name in the Twi language, "Akwakora bedi" (translated old man would eat), suggests that elderly men can even grow this hybrid and yet enjoy from its harvests. Freshly harvested and physiologically matured pods were collected from the Seed Production Division (SPD) of COCOBOD at Asikuma in the Central Region.

2.2. Growth Conditions. The experiment was conducted at the Technology Village of the School of Agriculture, University of Cape Coast (UCC), from August to November, 2016. Temperature and relative humidity ranged between approximately $24^{\circ} \mathrm{C}$ to $32^{\circ} \mathrm{C}$ and $60 \%$ to $80 \%$, respectively. Day length and solar radiation of the region ranges were approximately between 11.30 to 12.40 hours and $3151 \mathrm{~kJ} \mathrm{~cm}^{-2} \mathrm{day}^{-1}$ to $3804 \mathrm{kJcm}^{-2} \mathrm{day}^{-1}$, respectively [9]. Topsoil (0-15 cm depth) was collected from a site near the Teaching and Research Farm of UCC $\left(5.1155^{\circ} \mathrm{N}, 1.2909^{\circ} \mathrm{W}\right)$. The soil was typical of arable soils of the area and defined as Acrisols (FAO classification). The soil was a sandy loam with a $\mathrm{pH}$ of 6.1 and contained $2.2 \%$ organic carbon, $0.5 \%$ total nitrogen $(\mathrm{N})$, $26.1 \mu \mathrm{g}$ phosphorus $(\mathrm{P}) \mathrm{g}^{-1}$, and $6.1 \mathrm{cmol} \mathrm{kg}^{-1}$ exchangeable potassium $(\mathrm{K})$. The topsoil was air-dried and passed through a $2 \mathrm{~mm}$ sieve to remove coarse material and vegetative matter. The topsoil was then mixed uniformly with farm yard manure (FYM) in a 1: 0.5 ratio and composted for three weeks. Black nursery bags with drainage holes underneath and of size $17 \mathrm{~cm} \times 23 \mathrm{~cm}$ were filled with the soil/FYM mixture to a bulk density of approximately $1.1 \mathrm{~g} \mathrm{~cm}^{-3}$. The nursery bags were filled with the prepared growth medium to the specific depth and weighed to ensure the same amount of soil in each bag. The drainage outlets at the bottom of the bags were small enough to prevent the loss of soil but not drainage of excess water. The experiment was conducted in the open field under a shed made of sticks, split bamboo, and palm fronds. After sowing, soil-filled bags were watered using tap water at three-day intervals to approximately $70 \%$ field capacity (FC) on weight basis. Watering was temporarily suspended after every rainfall and resumed when the medium showed signs of drying and water content was found to be below 70\% FC. The soil-filled bags were kept weed-free manually.

2.3. Seed Mucilage Removal and Seed Storage. Seeds from different pods but of the same genetic material were opened on the day of harvest and mixed to form a composite sample which was then divided equally into two sets, representing "mucilage intact" and "demucilaged" seeds, respectively. No further treatment was given to the first set (mucilage intact seeds) prior to storage. Demucilaged seeds were obtained from the second set. Here, the seeds were gently washed to remove the mucilage according to local farmers' practices. To achieve this, the seeds were submerged, together with strips of dry maize husks, in tap water in a plastic basin for approximately ten minutes and then shaken gently and rapidly several times, until no more mucilage was released from them. The maize husk acted as a sponge and helped remove the mucilage from the seeds through its abrasive effect. Strips of husk from three dry maize ears were enough for about 300 seeds that were demucilaged. The demucilaged seeds settled at the bottom of the basin. The supernatant water, containing suspended mucilage removed from the seeds, was decanted. Some of the demucilaged and mucilage intact seeds were selected for fresh sowing. The remaining seeds (both in the demucilaged and mucilage intact sets) were then stored in labelled containers lined with cotton material and kept indoors at ambient temperature for the various storage durations investigated in this study. Stored seeds were sprinkled with tap water and gently stirred daily to minimize surface drying.

2.4. Seedling Emergence Experiments. The experiment was laid out in randomised complete block design (RCBD) of three blocks with five main treatments (storage) and two 
subtreatments (seed mucilage manipulation). The choice of RCBD was to allow us to account for confounding factors including pest and disease incidence that may arise under the shed. Originally, the seeds investigated for storage duration were seeds stored for $0,3,6,9$, and $12 \mathrm{~d}$ after demucilaging. Each storage treatment also had a subtreatment of either intact mucilage or demucilaged seeds, giving a total of ten treatments for each block. One seed was sown per nursery bag so there were 150 bags in each block and 450 bags for the three blocks (i.e., 5 storage durations $\times 2$ mucilage manipulations $\times 15$ reps $\times 3$ blocks). The soil-filled bags with seeds were randomly placed in each block on the ground and the locations of pots were changed daily within the blocks. Based on initial results, additional five storage treatments incorporating only demucilaged seeds were added. This addon experiment was meant to be a continuation of the initial set up and so demucilaged seeds were stored for 15, 18, 21, 24 , and $27 \mathrm{~d}$ after depulping. Replication and blocking were similar to the original design. The seeds were sown by sideorienting each seed at a depth of $2 \mathrm{~cm}$ in the soil/FYM-filled black nursery bags.

2.5. Data and Analyses. Prior to termination of experiment, data were taken on ten randomly selected plants per treatment during periodic data taking schedules. The nursery bags were monitored daily and germination parameters including days to seedling emergence, rate of germination, days to cessation of germination, and germination percentage were taken or derived. A seedling was considered to have emerged when its height exceeded $3 \mathrm{~mm}$ above the soil surface in the bags. The number of emerged seedlings was counted daily to calculate the time to reach $50 \%$ germination, which gave an estimate of germination rate, and was calculated using

$$
T_{50}=t_{i}+\frac{\left((N / 2)-n_{i}\right)\left(t_{j}-t_{i}\right)}{n_{j}-n_{i}},
$$

in reference [5], where $N$ is the final number of emergence and $n_{i}$ and $n_{j}$ are the cumulative number of seeds germinated by successive counts at times $t_{i}$ and $t_{j}$ when $n_{i}<N / 2<n_{j}$.

The number of days from the commencement of germination to completion or cessation was counted to determine time taken to end germination. Germination percentage was calculated as the quotient of total number of germinated seeds to number of seeds sown multiplied by 100 .

Measurement of growth performance parameters commenced two weeks after germination in each treatment and continued biweekly for three months. Parameters measured included plant height (height from soil surface to the growing tip), number of leaves (biweekly count of leaves on tagged plants), leaf area (length $\times$ breath $\times 0.75$ of tagged leaves), plant girth (measured by a calliper in millimetres, $2 \mathrm{~cm}$ from the soil surface), and shoot dry matter (weight in grams of 48 hour oven-dried shoots taken on the last day of the experiment). Root system architectural traits taken included root dry weight, length of the taproots, and root length density. Root dry weight was the weight of 48 hour oven-dried roots from harvested samples on the last day of the experiment. To determine length of the primary root and root length density, harvested roots on the final day of the experiment were thoroughly washed of soil, suspended, and spread in water in a rectangular glass dish with black background. Images of roots were captured with a Canon EOS 70D DSLR camera (https://www.usa.canon.com/) held stationary on a tripod $50 \mathrm{~cm}$ above roots. The length of the primary root in centimetres was recorded by measuring from the hypocotyl-root junction to the tip of the taproot using free hand tracing in ImageJ (US National Institutes of Health, Bethesda, MD, USA, https://imagej.nih.gov/ij/). Total root length was extracted through skeletonization of root images using ImageJ (US National Institutes of Health, Bethesda, MD, USA, https://imagej.nih.gov/ij/). Root length density was derived as quotient of total root length and the soil volume within which the seedlings were grown.

Count data were transformed through square root transformation following assessment for normality on the collected data. Data for seedling emergence shoot growth and RSA were analysed by two-way ANOVA, in which seed storage duration and mucilage manipulation and their interaction were the factors. Means were separated by least significant difference (l.s.d) and differences between means were considered significant at the $p<0.05$ level. Data in Figures are presented as arithmetic means \pm SE. All statistical procedures were performed using the GenStat Release 10.3DE, Discovery Edition 4, 2016 (VSN International Limited, Rothamsted Experimental Station, Hemel Hempstead, UK).

\section{Results}

3.1. Seedling Emergence. Storage duration, mucilage manipulations, and their interactions significantly affected germination percentage $(p<0.05)$ from 3 days of storage (Figure 1 , primary axis). Within treatments, there was no significant difference in germination percentage in demucilaged seeds sown after seed storage duration of up to 18 days (Figure 1, primary axis). After extracted seeds have been stored for 12 days, there was still $98 \%$ germination if the seeds were demucilaged, but germination percentage in intact seeds declined to below $20 \%$ in seeds stored for same period (Figure 1, primary axis). Acquisition of data on intact seeds was therefore suspended from day 12 of storage but data on demucilaged seeds continued to be taken to determine when its germination will decline to about $50 \%$. Two-way ANOVA showed that germination rate was significantly affected by storage duration, mucilage manipulation, and their interaction (Figure 1, secondary axis). With the exception of seeds that were sown on the day of extraction from the pod, germination rate of intact mucilage seeds was lower than that of demucilaged seeds for all storage durations (Figure 1, secondary axis). Whilst germination rate increased with increasing storage duration in demucilaged seeds from approximately 4.0 seeds day ${ }^{-1}$ at day 0 to 10 seeds day ${ }^{-1}$ at day 18 , it decreased with increasing storage duration in intact mucilage seeds and declined to almost zero after 3 days of seed storage (Figure 1, secondary axis). In demucilaged seeds, germination rate declined from 21 days of storage (Figure 1, secondary axis). 


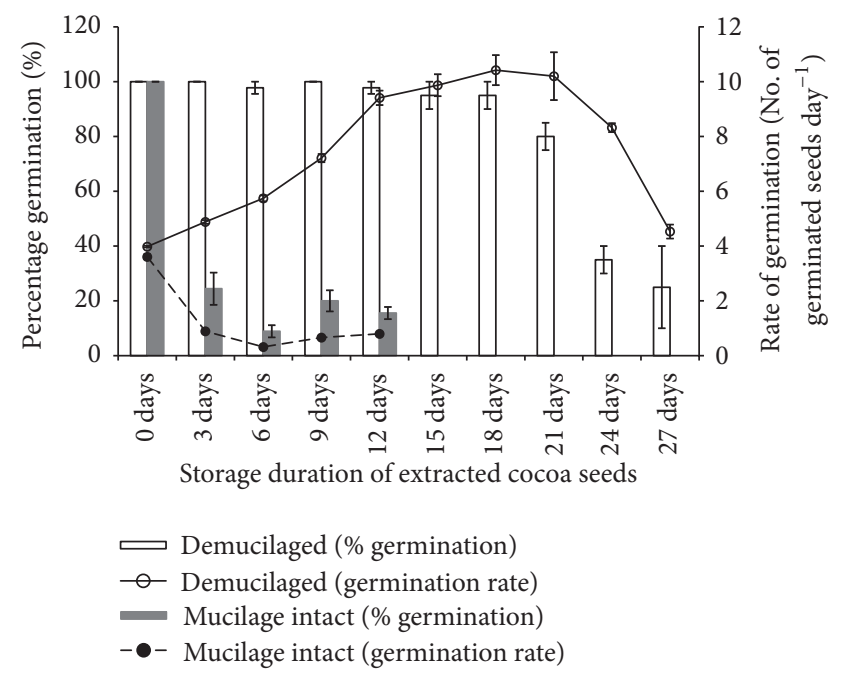

FIGURE 1: Percentage germination (bars on primary axis) and rate of germination (line and markers on secondary axis) of cocoa seeds with different seed mucilage manipulations at different seed storage durations (data are means; error bars \pm standard error means (s.e.m), $n=30$ ).

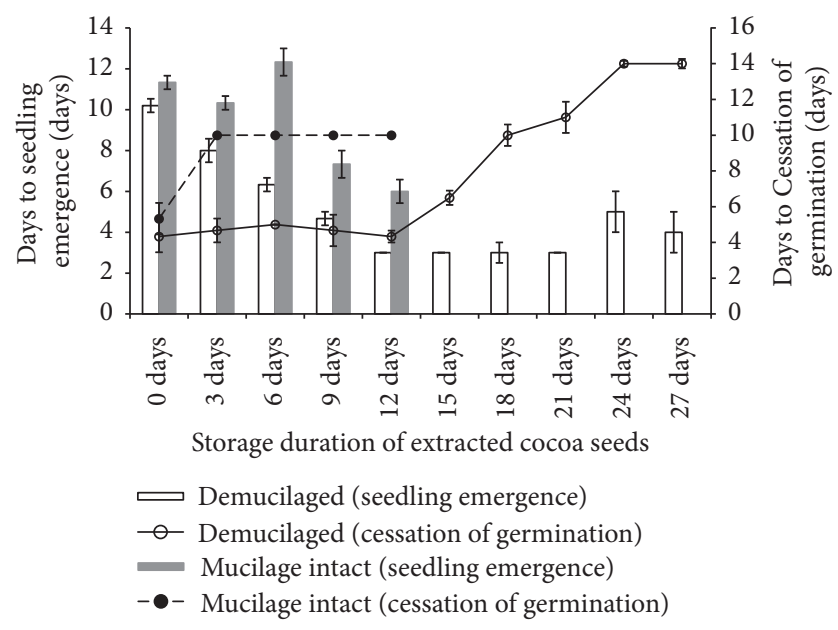

FIGURE 2: Effects of seeds storage duration and mucilage manipulation of cocoa seeds on days to seedling emergence (bars and primary axis) and days to cessation of germination (line and markers on secondary axis) (data are means and bars indicate \pm s.e.m, $n=30$ ).

\subsection{Days to Seedling Emergence and to Cessation of Germina-} tion. The seed storage duration and mucilage manipulation significantly affected days taken for seedling to emerge and for germination to cease but these differences were observed from 3 days of seed storage. The interactions between seed storage duration and mucilage manipulation were also significant (Figure 2). Nonstored seeds (both intact mucilage and demucilaged seeds) took up to 11 days after sowing to emerge (Figure 2, primary axis). Up to 12 days of seed storage, days taken by demucilaged seeds to emerge were consistently and significantly lower than those of mucilage intact seeds (Figure 2, bars on primary axis). In demucilaged seeds, number of days taken for seedlings to emerge declined with increasing seed storage duration. For example, demucilaged seeds stored for three days emerged after eight days of sowing whilst seeds stored for 21 days emerged three days after sowing (Figure 2, primary axis). The reverse was true for seeds with their mucilage intact.

No significant difference was observed in days to cessation of germination between demucilaged and intact seeds at day zero of seed storage. After germination had begun, demucilaged and intact seeds that were sown immediately after extraction from the pod (day zero storage) took approximately five days to terminate germination. Two-way ANOVA showed a significant difference $(p<0.05)$ in days taken to termination of germination between intact and demucilaged seeds that were stored for three to twelve days after extraction from pods (Figure 2, line and markers on secondary axis). From three to twelve days of seed storage, it took ten days and approximately five days for germination to be terminated in seeds with intact mucilage and demucilaged seeds, respectively (Figure 2, line and markers on secondary axis). In demucilaged seeds, days to cessation of germination increased from approximately seven days (in seeds stored for fifteen days) to 14 days (for seeds stored for 27 days after extraction) (Figure 2, line and markers on secondary axis).

3.3. Seedling Growth. Two-way ANOVA revealed that seedling growth parameters including plant height, number of leaves, leaf area, and plant girth were significantly affected by seed storage duration, mucilage manipulation, and their interaction but these differences were observed for seeds which were stored for three days or more but not those sown immediately after extraction from the pod (Tables 1(a) and 1(b)). Generally, for all sampling dates (biweekly sampling from week 2 to week 12), height and girth of plants and number and area of leaves were consistently and significantly superior in demucilaged seeds (Tables 1(a) and 1(b)). Generally, within treatments and for all sampling dates, height and girth of plants and number and area of leaves were not significantly different between demucilaged seeds stored for $0,3,6,9,12,15,18$, and 21 days (Tables $1(\mathrm{a})$ and $1(\mathrm{~b})$ ). On the other hand, height and girth of plants and number and area of leaves were significantly different between seeds with mucilage intact which were stored for $0,3,6,9$, and 12 days (Tables 1(a) and 1(b)). Within the intact mucilage treatment, values for all the parameters measured generally declined with increasing storage duration (Tables $1(a)$ and $1(b)$ ).

Shoot and root biomass were significantly $(p<0.05)$ affected by seed storage duration, mucilage manipulation, and their interaction but these differences were observed for seeds which were stored for 3 days or more but not those sown immediately after extraction from the pod (Figure 3 ). For all sampling dates (week 2 to 12), shoot and root dry biomass were generally significantly $(p<0.05)$ higher in demucilaged seeds than in seeds with intact mucilage (Figure 3 ). Within treatments, shoot and root biomasses were generally not significantly different in the demucilaged seeds stored for various durations (Figure 3). On the other hand, whilst shoot and root dry weight of intact mucilage seeds declined with increasing storage duration, shoot and root biomass of seeds 


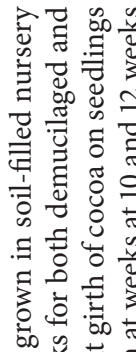

o

$\exists$ 范

ญ그뮤 훙

สี ี

范芯

琎

\& 3

过苛

팡 경

苍

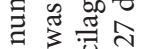

䒕苋苦

븡

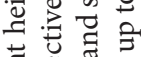

䒕颔

ธิ की

ธี స్ㅎㅀ

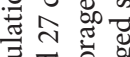

른 $\overrightarrow{0}$

글

$\therefore$ 웅

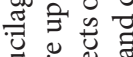

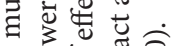

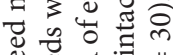

幽范

द्व

5ี

氜產苛

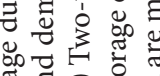

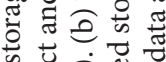

के प्ü

⿶.

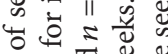

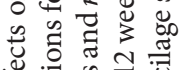

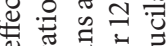

㟧

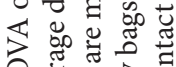

之 क

过

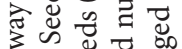

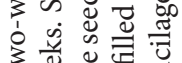

उ एँ

త 3 ज्ञ

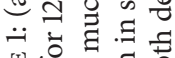

떠원

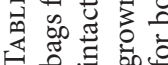

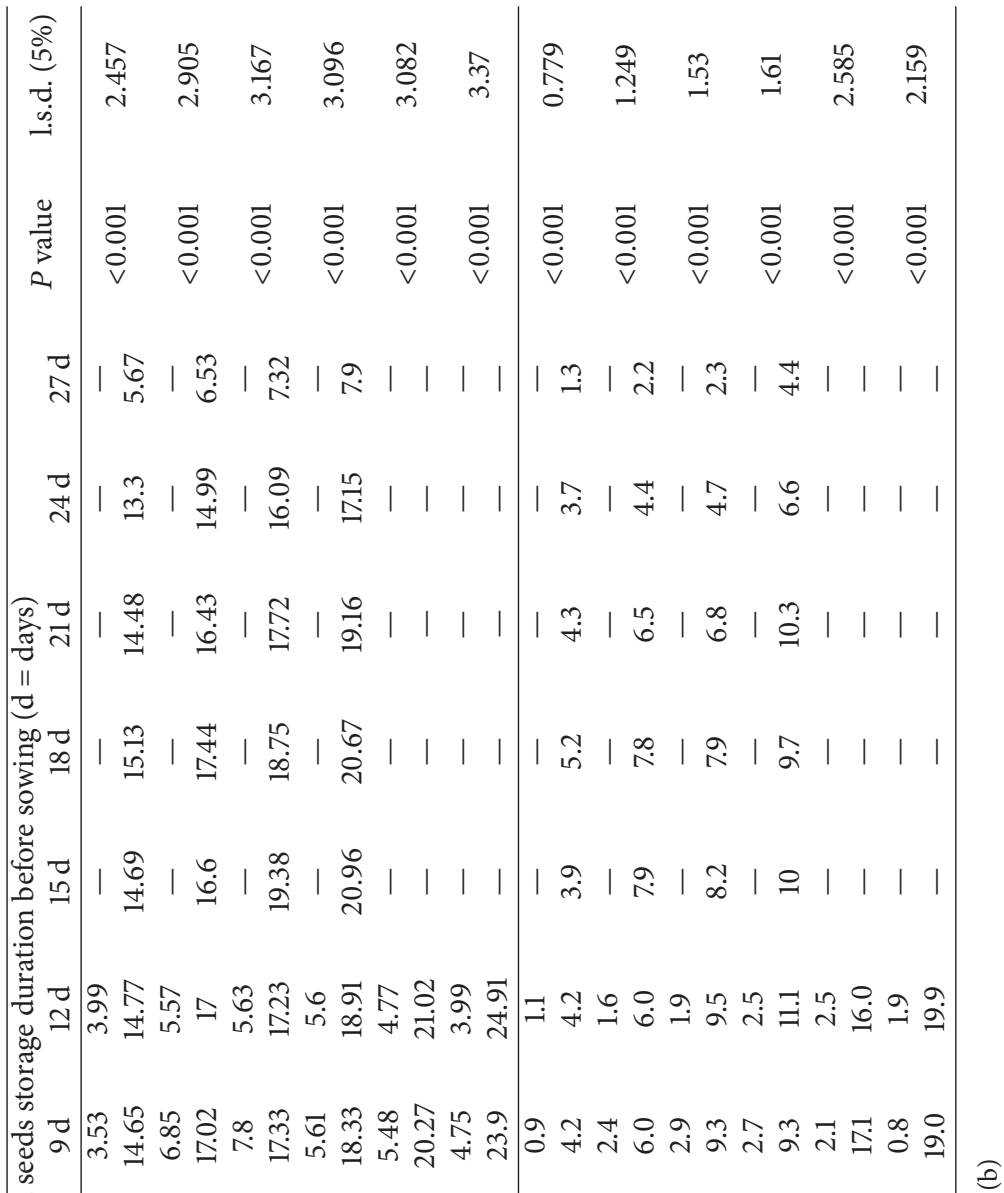

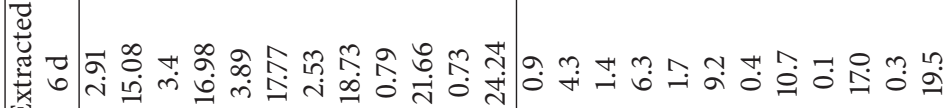

II

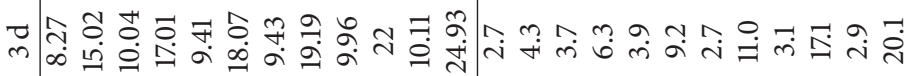

ت

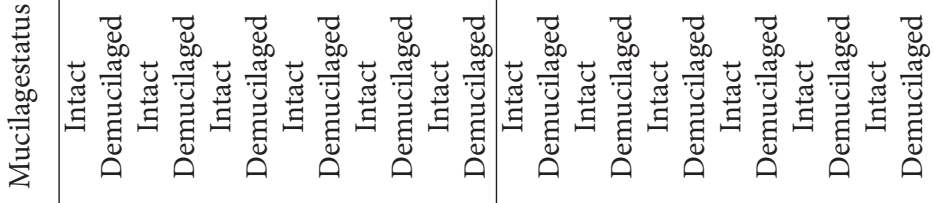

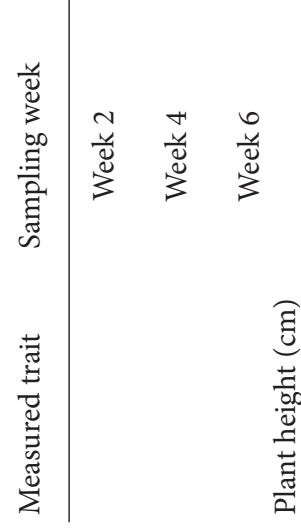

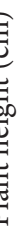

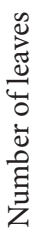

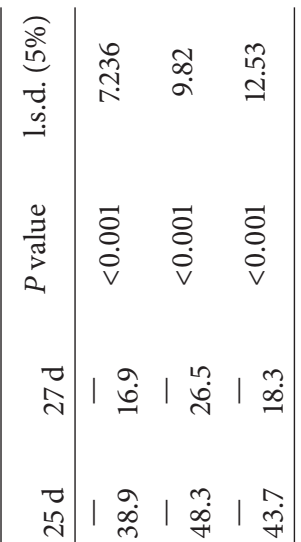

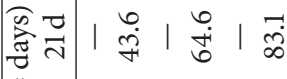

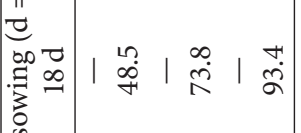

总

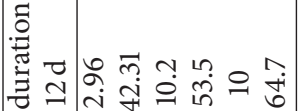

竎

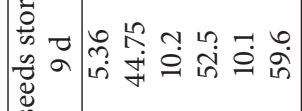

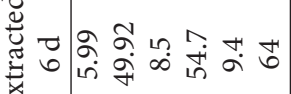
乐

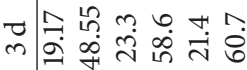

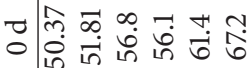

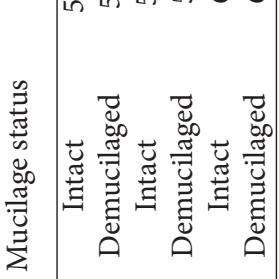

चै

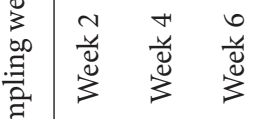




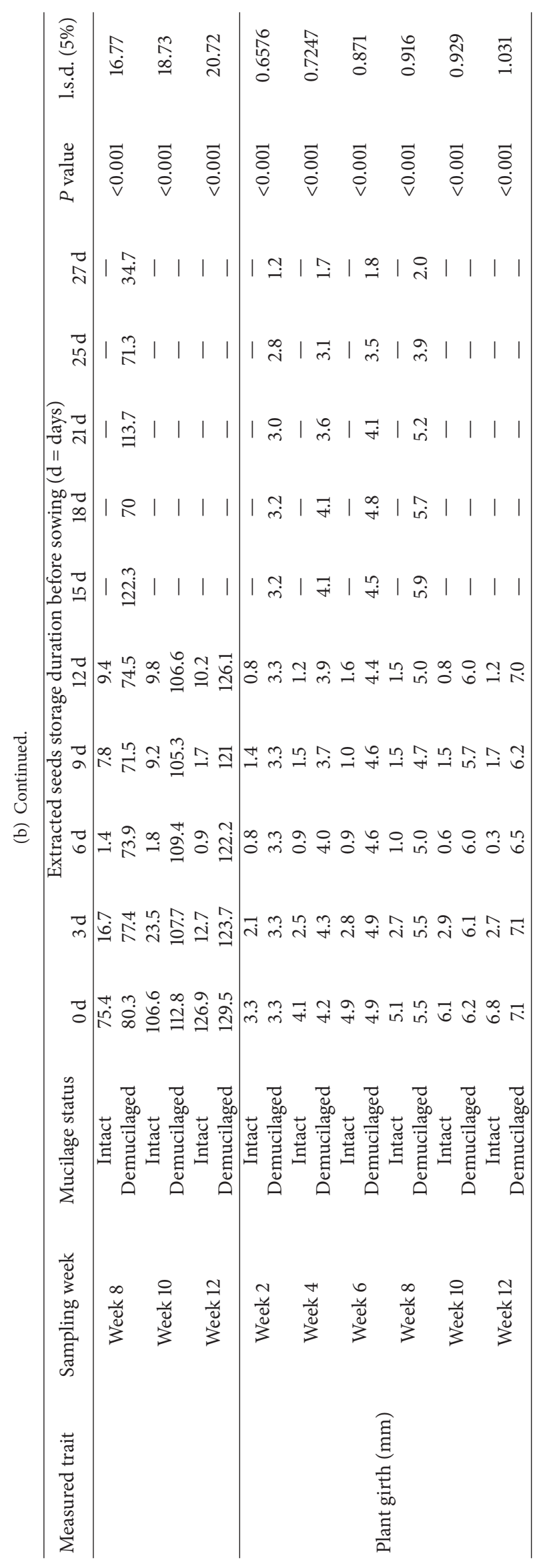




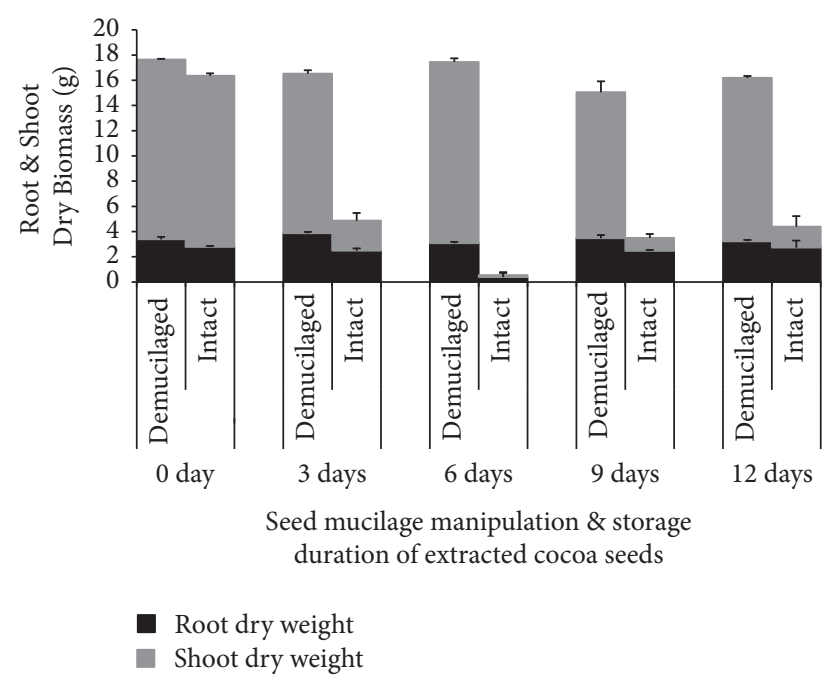

Figure 3: Effects of seeds storage duration and seed mucilage manipulation of on shoot and root dry biomass cocoa seedlings grown in soil-filled nursery bags for 12 weeks under a nursery shed (data are means and bars indicate + s.e.m, $n=45$ ).

stored for 6 days were unusually lower than those for other storage durations for the same mucilage treatment (Figure 3).

3.4. Root System Architecture. Roots grew well in the soilfilled bags but differences between RSAs from intact mucilage and demucilaged seeds were immediately obvious when root were excavated and washed (Figure 4). Root systems from demucilaged seeds showed no or less abnormalities and consisted of a prominent primary root and several symmetrically branched first-order lateral roots which emerged from the primary root. There were numerous second-order laterals also (Figure 4). On the contrary, RSAs of seedlings produced from mucilage-intact seeds had no prominent primary roots or the primary roots were shorter. Also, they had few or no lateral roots and, if present, were not symmetrically branched. On occasions, there appeared to be two primary roots in the root system of one seedling and second-order lateral roots were also rare (Figure 4). Root systems from seeds with intact mucilage stored for three and six days seemed the most deformed (Figure 4).

Analysis of variance indicated that there was a significant difference $(p<0.05)$ in length of primary roots between demucilaged and intact mucilage seeds but this variation was not observed in seeds that were not stored before sowing (Figure 5). Primary root lengths were longer in demucilaged seeds than in intact mucilage seeds. Within treatments, the primary root length of all demucilaged seeds did not differ regardless of the length of storage period (Figure 5). However, within treatments of intact seed mucilage, length of primary root significantly differed $(p<0.05)$ between various storage durations with a generally decreasing trend in primary root length with increasing seed storage duration (Figure 5, bars on primary axis). A similar trend was observed in the analyses of root length density where there were significant differences $(p<0.05)$ in root length density between demucilaged and intact mucilage seeds for all stored seeds but not for seeds sown immediately after extraction from the pod (day 0 seeds; Figure 5, line and markers on secondary axis). Again, root length density values recorded for intact seeds that were stored for six days suggested that something was inherently wrong with that treatment (Figure 5, line and markers on secondary axis). Root length density was not significantly different in seedlings grown from demucilaged seeds for all storage durations but storage treatment significantly affected root length density in seeds with intact mucilage, with seedlings grown from seeds stored for six days, again recording very low values (Figure 5, line and markers on secondary axis).

\section{Discussion}

Cocoa (Theobroma cacao L.) has huge economic significance in Ghana, providing livelihoods for both small and large scale farmers. Cocoa is propagated sexually using seeds from ripe pods. A cocoa seed consists of two cotyledons and an embryo (radicle) contained within a seed coat (testa). The seed coat is completely enveloped in a sweet, white, mucilaginous pulp that comprises approximately $40 \%$ of seed fresh weight [10]. Seed mucilage is very essential in many seed mucilage-bearing plants. Some of the important attributes of seed mucilage include its ability to prevent drying of seeds, reduce drought stress during germination, and facilitate rapid germination and early seedling establishment and growth $[5,6,11,12]$. Seed mucilage also plays important roles in seed dispersal, seed adhesion to soil, and minimizing seed removal by water and predators $[6,13]$. Although literature is replete with advantages of seed mucilage, especially its role in propagation, inhibiting effects of mucilage have also been recorded for seeds of several species $[11,14]$.

For many cocoa farmers in Ghana who produce their own seedlings or sow directly from seeds due to inaccessibility of seedlings provided by the Government, there is still some doubt regarding the advantages or otherwise of seed mucilage on seedling emergence and establishment, especially when the seeds have to be stored for some days before sowing. In fact, this conundrum is neither new nor exclusive to Ghanaian cocoa farmers. Hardy [15] reported that farmers in different parts of the world either removed the mucilage before sowing or kept it intact. Farmers in favour of removing the mucilage before sowing suggested that doing so accelerated germination by a few days. Others on the opposing end argued that the slight gain in germination time was not worth the toil involved in removing the seed mucilage before sowing.

The current study shows that demucilaging cocoa seeds confers several advantages over mucilage intact seeds provided the seeds would be stored for at least three days before sowing. The results showed that demucilaging increased germination rate $\left(T_{50}\right.$ or $50 \%$ germination $)$ and percentage germination (Figure 1), and presence of mucilage increased days to seedling emergence and cessation of germination (Figure 2) when seeds were stored for three or more days. Seedlings produced from demucilaged seeds were also superior in growth parameters, (plant height and girth and leaf number and area), in plant biomass parameters (shoot and root dry weight) and in root system parameters (primary root 


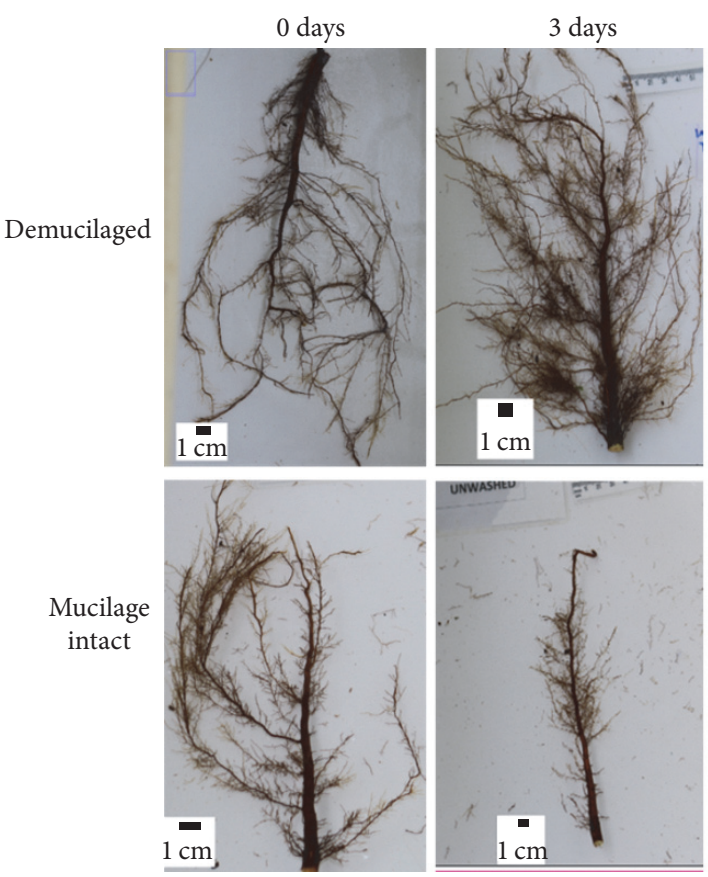

Seed storage duration
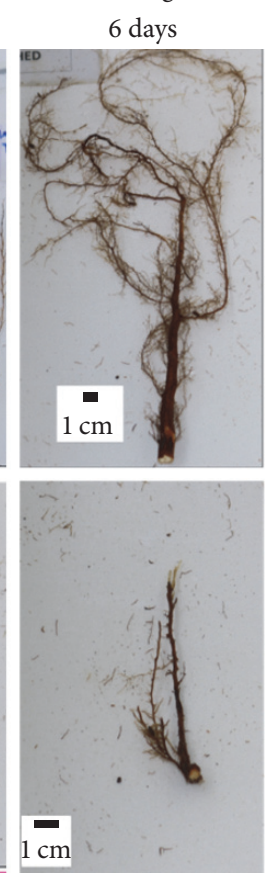
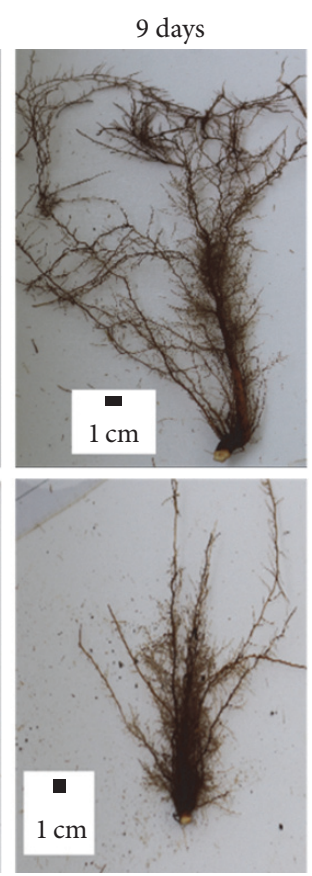
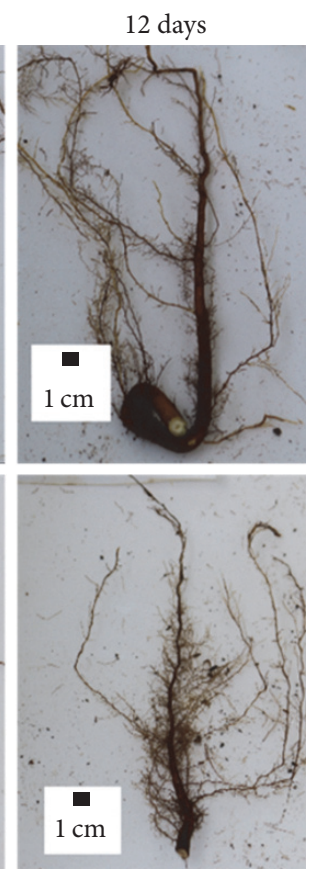

FIGURE 4: Examples of images showing the effects of seeds storage duration and seed mucilage manipulation on root system architecture of cocoa seedlings grown in soil-filled nursery bags for 12 weeks under a nursery shed.

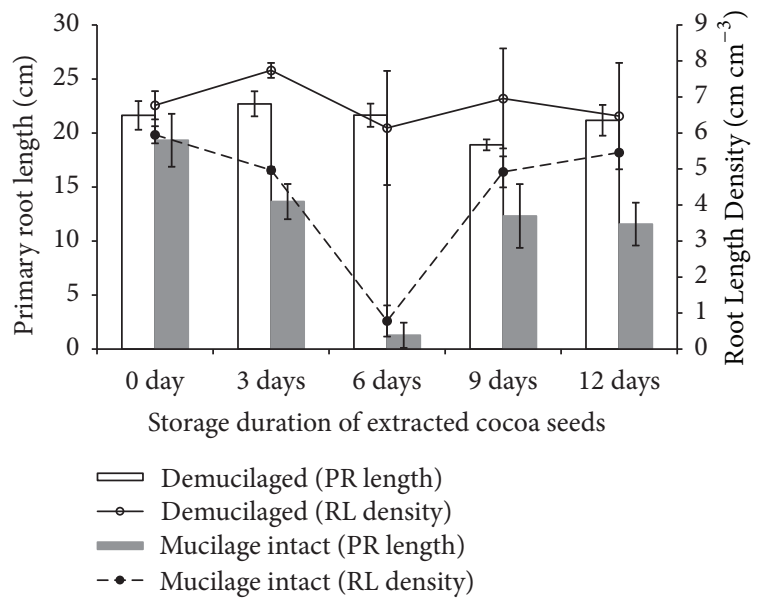

FIgURE 5: Effects of seeds storage duration and seed mucilage manipulation on primary root length (bars, primary axis) and root length density (line and markers, secondary axis) of cocoa seedlings grown in soil-filled nursery bags for 12 weeks under a nursery shed (data are means and bars indicate \pm s.e.m, $n=45$ ).

length and root length density) to that of seedlings produced from intact mucilage seeds (Table 1, Figures 3, 4, and 5). If seeds were sown on the very day of extracting them from physiologically mature ripe pods, seedling emergence, growth, biomass, and root system parameters measured were comparable between demucilaged and intact mucilage seeds (Table 1, Figures 1-5). Enhancing effects of seed mucilage on seedling emergence and establishment previously reported by others were attributed to high water-retaining capacity of mucilage in arid conditions $[5,7,16,17]$. In the current study, water was not limiting and was therefore not unexpected that emergence and growth in intact seeds were not superior to that in demucilaged seeds when seeds were sown without storage. Whilst it is recommended that cocoa seeds should be sown immediately upon extraction [15], the result herein suggests that if seeds are sown on the day of extraction, removing the mucilage prior to sowing would be unnecessary.

The current study was also based on the fact that smallholder farmers in Ghana occasionally store their propagating materials (pods and or seeds) beyond one week due to factors including unplanned but obligatory social engagements [2]. Furthermore, if viability of stored fresh cocoa seeds could be confirmed, it would reduce cost and toil faced by remote farmers in Ghana in conveying hybrid seeds supplied by the Seed Production Division (SPD) of COCOBOD to their farms. The next question in the present study was thus to determine whether mucilage enhances seedling emergence and establishment when fresh cocoa seeds are stored before sowing. First, the results show that seedlings produced from mucilage intact seeds sown fresh from pods performed better in all parameters measured than those from same seeds stored before sowing. Such superior seedling performance from nonstored seeds could be attributed to the availability of food reserves which might be low in stored seeds due to microbial respiration [2].

Second, the results show that, up to 21 days of seed storage, there was generally no difference in many traits measured (such as percent germination, plant height, shoot dry weight, and primary root length) of demucilaged seeds. Third, demucilaged seeds recorded 80 to $100 \%$ germination after 21 days 
of storage and rate of germination increased with increasing duration of seed storage (Figure 1). However, intact mucilage seeds maintained 80 to $100 \%$ germination for only 2 days after seed extraction and rate of germination decreased with increasing seed storage duration (Figure 1). It is noteworthy that seeds for both treatments were sprayed daily with water to prevent drying during storage. The result here therefore suggests that demucilaging and storage can provide considerable advantages to smallholder farmers when environmental or socioeconomic conditions preclude immediate sowing of seeds. Fourth, seedling emergence, growth, biomass, and root system features in stored seeds were superior in demucilaged seeds for all sampling dates (Table 1; Figures 3-5). Amoah $[4,18]$ reported similarly that demucilaged cocoa beans sprouted faster and recorded higher percentage germination. The results in the current study agree with other reports for several other seed-mucilage-bearing species. For example, removing the seed mucilage reportedly favoured the percentage, speed, uniformity of germination, and early development in papaya (Carica papaya [19]), guava (Psidium guajava [20]), citrus [21], red dragon (Hylocereus undatus Haw [22]), passion fruit (Passiflora edulis [23-25]), alyssum (Alyssum minus [13]), and lettuce (Lactuca sativa [26]).

It is evident from the foregoing results that removal of mucilage in cocoa seeds and storing enhanced germination and growth of seedlings. It is possible that the removal of mucilage rather facilitated imbibition of water through direct contact, with a resultant rise in metabolic activities within the seed [27]. For example, [6] reported that germination of seeds in Dillenia indica (Dilleniaceae) was enhanced when mucilage was washed off from the seeds, thus allowing them to imbibe water and germinate. Could it also be that there was relatively higher surge in free fatty acids (FFAs) in mucilaginous seeds during storage thus hampering water absorption [4]? It has been suggested that chemical components of cocoa such as FFAs are affected by postharvest treatments including pod storage and fermentation, such that increasing pod storage duration increases the percentage FFAs [28]. The possibility of germination-inhibiting levels of FFAs in the mucilage of stored cocoa seeds appears likely since an increase in FFAs has been associated with a decrease in germinability and vigour [29]. The possible accumulation of inhibitory substances in intact mucilage seeds may have induced the appearance of abnormal seedlings and necrosis of the roots [30], explaining the observed abnormal RSA with reduced PRL and RLD.

It appears that the presence of mucilage on freshly stored seeds of cocoa (Theobroma cacao) accelerates loss of seed viability and/or vigour in storage due to physiological deterioration with time. This deterioration may be accumulated damage as a result of potentially impaired mechanisms including alterations of enzyme structure, degradation of cell membranes, and release of phenolic compounds leading to the loss of enzyme activity [31-33]. Perhaps a more plausible reason explaining these impaired mechanisms and its attendant reduced germinability and vigour in the mucilagebearing seeds in the present study would be fermentation. Cocoa mucilage consists of about $87 \%$ water, $15 \%$ sugar, $3 \%$ pentosans, $3 \%$ citric acid, and $1.5 \%$ pectin [34]. Proteins, amino acids, vitamins (mainly vitamin $\mathrm{C}$ ), and minerals are also present, making the seed a rich medium for microbial growth [34]. Although the seeds within the cocoa ripe pod are microbiologically sterile, when the pod is opened, the mucilage becomes contaminated with a variety of microorganisms (e.g., bacteria and yeast) many of which contribute to the subsequent fermentation $[10,35,36]$. According to [37] fermentation leads to the production of ethanol and acetic acid which penetrates into the seed to kill the embryo of the seed. Fermentation would have broken down seed and or seedling food reserves and slowed down growth and reduced photosynthetic rates of the seedlings [18]. The higher and faster rate of germination and seedling growth generally obtained from stored demucilaged seeds could thus be attributed to reduced fermentation, resulting in higher availability of food reserves for the seeds and growing seedlings.

\section{Conclusion}

The present study showed that demucilaging cocoa seeds confers several advantages over sowing mucilage intact seeds provided the seeds would be stored for at least three days before sowing. The results here suggest that (i) if seeds are sown on the day of extraction removing the mucilage prior to sowing would be an unnecessary drudgery and (ii) demucilaging and storage can provide considerable advantages to smallholder farmers when environmental or socioeconomic conditions preclude immediate sowing of seeds.

\section{Competing Interests}

The authors declare that there is no conflict of interests regarding the publication of this paper.

\section{Acknowledgments}

The authors are grateful to Prof. Jonathan P. Tetteh of the Department of Crop Science, School of Agriculture, University of Cape Coast, for providing useful inputs to improve the manuscript.

\section{References}

[1] D. Mohammed, D. Asamoah, and F. Asiedu-Appiah, Cocoa value chain-implication for the smallholder farmer in Ghana [MPhil thesis], Department of Information Systems and Decision Sciences, KNUST School of Business, Kwame Nkrumah University of Science \& Technology, Kumasi, Ghana, 2011.

[2] J. K. Saajah and B. K. Maalekuu, "Determination of postharvest pod storage on viability and seedling growth performance of cocoa (Theobroma cacao L) in the nursery," Journal of Agricultural Science, vol. 6, no. 4, pp. 77-90, 2014.

[3] H. F. Chin, B. Krishnapillay, and P. C. Stanwood, "Seed moisture: recalcitrant vs. orthodox seeds," Seed Moisture, no. 14, pp. 15-22, 1989.

[4] F. M. Amoah, "The effect of seed treatment and depth of sowing on germination and seedling development in cocoa," Ghana Journal of Horticulture, vol. 4, pp. 45-51, 2005.

[5] X. Yang, C. C. Baskin, J. M. Baskin, G. Liu, and Z. Huang, "Seed mucilage improves seedling emergence of a sand desert shrub," PlOS ONE, vol. 7, no. 4, Article ID e34597, 2012. 
[6] R. C. Thapliyal, S. S. Phartyal, J. M. Baskin, and C. C. Baskin, "Role of mucilage in germination of Dillenia indica (Dilleniaceae) seeds," Australian Journal of Botany, vol. 56, no. 7, pp. 583-589, 2008.

[7] S. Penfield, R. C. Meissner, D. A. Shoue, N. C. Carpita, and M. W. Bevan, "MYB61 is required for mucilage deposition and extrusion in the arabidopsis seed coat," Plant Cell, vol. 13, no. 12, pp. 2777-2791, 2001.

[8] D. R. Glendinning, "Further developments in the breeding programme at the Cocoa Research Institute, Tafo," Ghana Journal of Science, vol. 6, pp. 52-62, 1966.

[9] L. Abbey and E. Oppong-Konadu, "Status of onion production in Ghana and prospects for improvement," Ghana Journal of Science, vol. 37, pp. 17-21, 1997.

[10] R. F. Schwan and A. E. Wheals, "The microbiology of cocoa fermentation and its role in chocolate quality," Critical Reviews in Food Science and Nutrition, vol. 44, no. 4, pp. 205-221, 2004.

[11] N. C. Garwood, "The role of mucilage in the germination of cuipo, Cavanillesia platanifolia (H. \& B.) H. B. K. (Bombacaceae), a tropical tree," American Journal of Botany, vol. 72, no. 7, pp. 1095-1105, 1985.

[12] Y. Gutterman and S. Shem-Tov, "Structure and function of the mucilaginous seed coats of Plantago coronopus inhabiting the Negev desert of Israel," Israel Journal of Plant Sciences, vol. 44, no. 2-3, pp. 125-133, 1996.

[13] Y. Sun, D. Y. Tan, C. C. Baskin, and J. M. Baskin, "Role of mucilage in seed dispersal and germination of the annual ephemeral Alyssum minus (Brassicaceae)," Australian Journal of Botany, vol. 60 , no. 5, pp. 439-449, 2012.

[14] S. F. L. Figueiredo, "Conservation viability of Cacao seed II. The fruit type and seed germination description," RevistaTheobroma, vol. 16, pp. 75-88, 1986.

[15] F. Hardy, Ed., Manual de Cacao, No. 633.74 H3Y, Instituto Interamericano de Ciencias Agricolas, Turrialba, Costa Rica, 1961.

[16] Z. Huang, I. Boubriak, D. J. Osborne, M. Dong, and Y. Gutterman, "Possible role of pectin-containing mucilage and dew in repairing embryo DNA of seeds adapted to desert conditions," Annals of Botany, vol. 101, no. 2, pp. 277-283, 2008.

[17] X. Yang, M. Dong, and Z. Huang, "Role of mucilage in the germination of Artemisia sphaerocephala (Asteraceae) achenes exposed to osmotic stress and salinity," Plant Physiology and Biochemistry, vol. 48, no. 2-3, pp. 131-135, 2010.

[18] U. M. Ndubuaku and T. C. N. Ndubuaku, "Effects of bean condition and sowing media on germination and nursery performance of some selected Theobroma cacao L. genotypes," in Proceedings of the 14th International Cocoa Research Conference Report, pp. 116-134, Accra, Ghana, 2001.

[19] E. O. Ono, J. F. Grana Júnior, and J. D. Rodrigues, "Plant regulators in breaking the apical dominance of papaya (Carica papaya L.)," Revista Brasileira de Fruticultura, vol. 26, no. 2, pp. 348-350, 2004.

[20] N. Rodriguez, M. Gordille, and S. Caballero, "Action of strong acids and different periods of immersion in water on the process of germination of guava seeds (Psidium guajava var. 'cotorrera')," Agricultural Science and Technology (Citrus and Other Fruit Trees), vol. 5, no. 4, pp. 99-106, 1982 (Spanish).

[21] P. D. T. L. Teixeira, G. Schäfer, P. V. D. de Souza, and A. Todeschini, "Chemical scarification and initial development of citric rootstocks," Revista Brasileira de Fruticultura, vol. 31, no. 3, pp. 865-871, 2009.
[22] A. R. Godoy, C. Z. Alves, and N. C. Oliveira, "Effect of removal of mucilage in germination and seed vigor of Hylocereus undatus Haw," Revista Brasileirade Ciencias Agrarias, vol. 7, no. 4, pp. 586-589, 2012.

[23] G. Ferreira, A. d. Oliveira, J. D. Rodrigues et al., "Efeito de arilo na germinação de sementes de Passiflora alata curtis em diferentes substratos e submetidas a tratamentos com giberelina," Revista Brasileira de Fruticultura, vol. 27, no. 2, pp. 277-280, 2005.

[24] C. Rossetto, R. Coneglian, J. Nakagawa, M. Shimizu, and V. Marin, "Germination of passion fruit seeds (Passiflora alata Dryand) as a function of pre-germinative treatment," Revista Brasileira de Sementes, vol. 22, no. 1, pp. 247-252, 2000 (Portuguese).

[25] A. R. São-José and J. Nakagawa, "Effects of fermentation drying on the germination of yellow passion fruit seeds," Revista Brasileira de Sementes, vol. 9, no. 2, pp. 35-43, 1987 (Portuguese).

[26] G. Candiani, M. Galetti, and V. J. Cardoso, "Seed germination and removal of Michelia champacaL. (Magnoliaceae) in eucalypt stands: the influence of the aril," Revista Árvore, vol. 28, no. 3, pp. 327-332, 2004.

[27] A. O. Dwapanyin and E. B. Frimpong, "The effects of bean size and shade on the growth and development of nursery cocoa seedlings," in Proceedings of the 15th International Cocoa Research Conference Report, pp. 110-180, Lagos, Nigeria, 2003.

[28] E. O. Afoakwa, E. Ofosu-Ansah, J. F. Takrama, A. S. Budu, and H. Mensah-Brown, "Changes in chemical quality of cocoa butter during roasting of pulp pre-conditioned and fermented cocoa (Theobroma cacao) beans," International Food Research Journal, vol. 21, no. 6, pp. 2221-2227, 2014.

[29] J. M. Halloin, "Changes in planting seed quality between ripening and harvest," in Proceedings of the Beltwide Cotton Production Research Conferences National Cotton Council, Memphis, Tenn, USA, 1981.

[30] A. G. Ferreira and E. A. Áquila, "Allelopathy: an area emerging of ecophysiology," Brazilian Journal of Plant Physiology, vol. 12, pp. 175-204, 2000 (Portuguese).

[31] H. F. Chin, Y. L. Hor, and M. B. Mohd Lassim, "Identification of recalcitrant seeds," Seed Science and Technology, vol. 12, pp. 429-436, 1984.

[32] W. D. Loomis and J. Battaile, "Plant phenolic compounds and the isolation of plant enzymes," Phytochemistry, vol. 5, no. 3, pp. 423-438, 1966.

[33] T. A. Villiers, "Ageing and the longevity of seeds in field conditions," in Seed Ecology, W. Heydecker, Ed., pp. 265-288, Butterworths, London, UK, 1972.

[34] D. T. O. Amanquah, Effect of mechanical depulping on the biochemical, physicochemical and polyphenolic constituents during fermentation and drying of Ghanaian cocoa beans [M.S. thesis], Department of Nutrition and Food Science, University of Ghana, Accra, Ghana, 2013.

[35] J. F. Takrama Abd and D. Adomako, Raw Cocoa Processing in Ghana, Cocoa Research Institute of Ghana, New Tafo, Ghana, 1996.

[36] L. Jespersen, D. S. Nielsen, S. Hønholt, and M. Jakobsen, "Occurrence and diversity of yeasts involved in fermentation of West African cocoa beans," FEMS Yeast Research, vol. 5, no. 4-5, pp. 441-453, 2005.

[37] M. P. Doyle, L. R. Beuchat, and T. J. Montville, "Food microbiology fundamentals and frontiers," in Cocoa and Coffee, chapter 35, pp. 721-733, ASM Press, Washington, DC, USA, 2nd edition, 2001. 

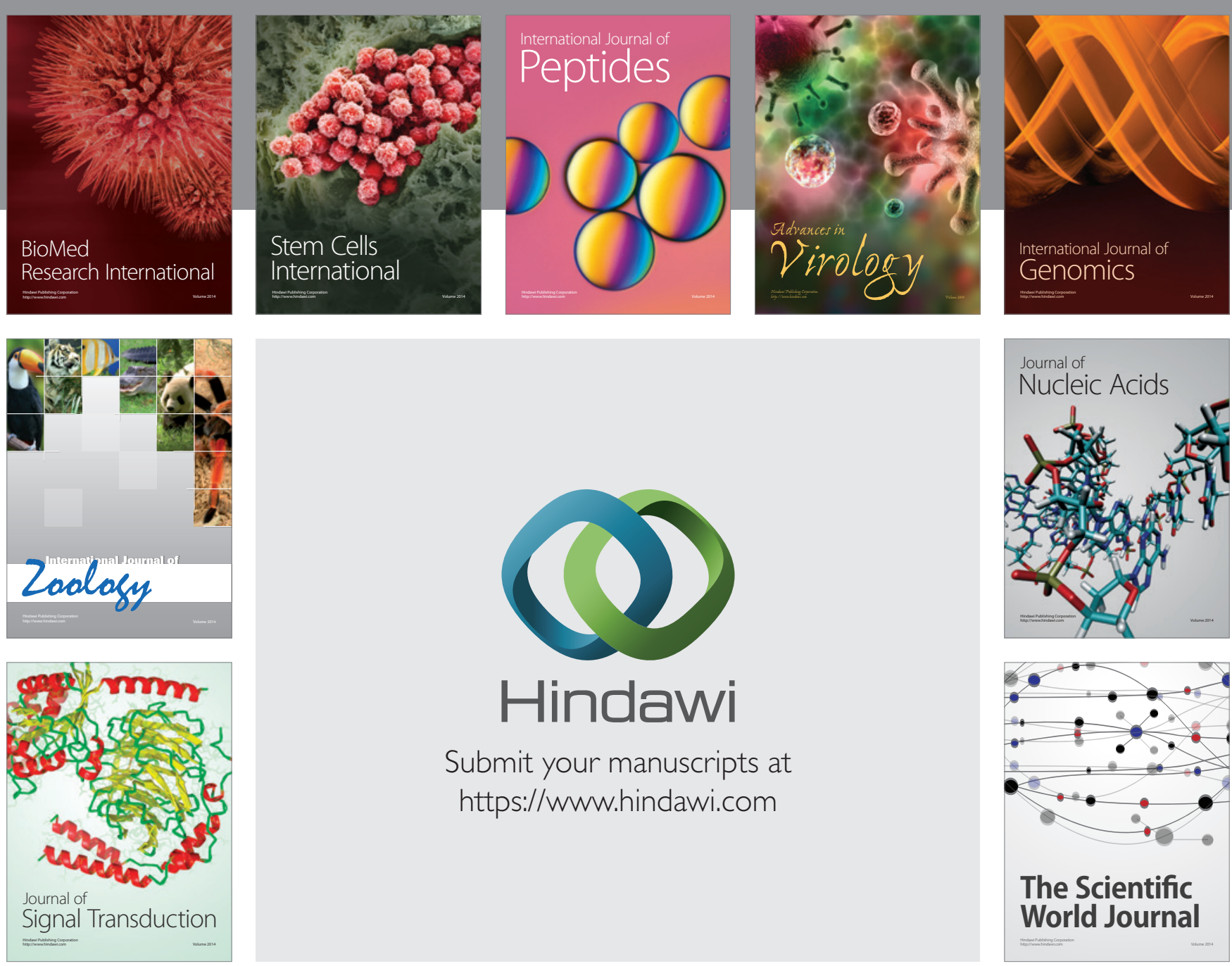

Submit your manuscripts at

https://www.hindawi.com
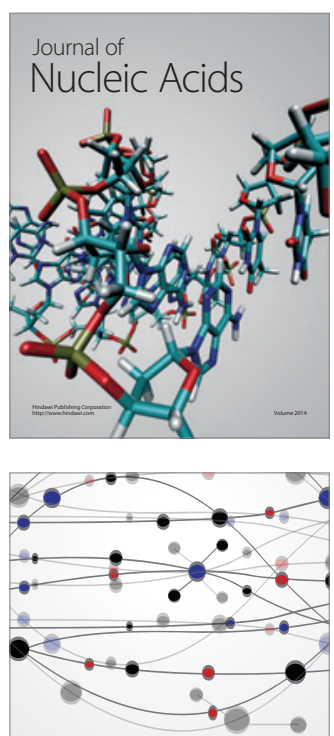

The Scientific World Journal
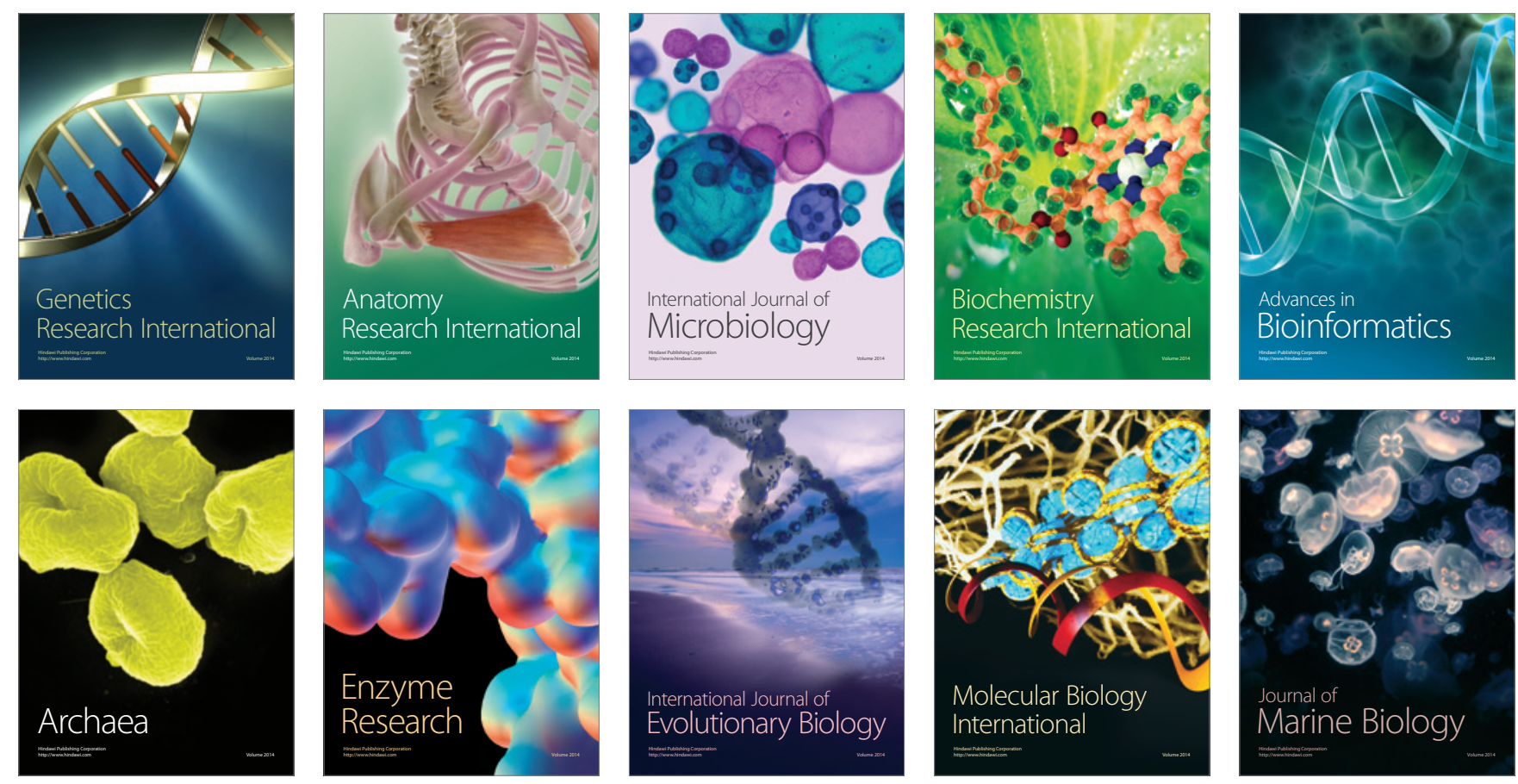